Int. J. Electrochem. Sci., 11 (2016) $10107-10122$

\title{
Highly Sensitive and Selective Determination of Dopamine Based on Ionic Liquid-Titanium Dioxide/Graphene Oxide Nanocomposite Modified Electrode
}

\author{
Chao-Zhi $\mathrm{Lv}^{1, \dot{\dagger}}$, Dan Chen ${ }^{1,2, \dot{\dagger}}$, Zhong Cao ${ }^{1, *}$, Feng Liu $^{1}$, Xiao-Mei Cao ${ }^{3}$, Jing-Lin He ${ }^{1}$, Wen-Yu Zhao ${ }^{1}$ \\ ${ }^{1}$ Hunan Provincial Key Laboratory of Materials Protection for Electric Power and Transportation, \\ School of Chemistry and Biological Engineering, Changsha University of Science and Technology, \\ Changsha 410114, PR China \\ ${ }^{2}$ Hunan Airbluer Environmental Protection Technology CO., LTD, Changsha 410019, PR China \\ ${ }^{3}$ College of Chemistry and Chemical Engineering, Hunan Normal University, Changsha 410081, PR \\ China \\ "E-mail: zhongcao2004@163.com \\ ${ }^{\dagger}$ These authors contributed equally to this work.
}

doi: $10.20964 / 2016.12 .01$

Received: 31 August 2016 / Accepted: 25 September 2016 / Published: 10 November 2016

A composite modified voltammetric sensor for dopamine (DA) was successfully developed, which was based on in-situ electrodepositing ionic liquids (IL, [BMIM]BF 4 )-titanium dioxide $\left(\mathrm{TiO}_{2}\right.$ ) nanoparticles on graphene oxide (GO) modified glassy carbon electrodes (GCE). The surface

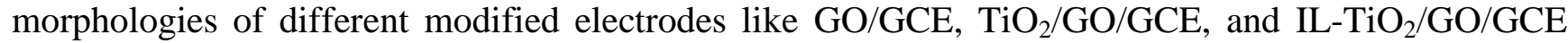
were characterized by scanning electron microscopy. The electrocatalytic activities of the corresponding electrodes to dopamine (DA) were investigated using cyclic voltammetry (CV) and differential pulse voltammetry (DPV), indicating that $\mathrm{IL}-\mathrm{TiO}_{2} / \mathrm{GO}$ exhibited much higher electrocatalytic oxidation activity for DA than GO/GCE and $\mathrm{TiO}_{2} / \mathrm{GO} / \mathrm{GCE}$. The response of the IL$\mathrm{TiO}_{2} / \mathrm{GO}$ modified electrode to DA was linear within a range of $8.0 \times 10^{-9} \sim 6.0 \times 10^{-5} \mathrm{~mol} \cdot \mathrm{L}^{-1}$, and the limit of detection was found to be $9.62 \times 10^{-10} \mathrm{~mol} \cdot \mathrm{L}^{-1}(\mathrm{~S} / \mathrm{N}=3)$. Furthermore, the fabricated electrode possessed good selectivity, reproducibility and stability, and was applied to quantitative determination of DA in human serum samples with a recovery rate of 98.6 103.2\%. The accuracy of the electrode was also comparable to that of a traditional spectrophotometric method, suggesting that the proposed method was of valuable in practical application on biomedical analysis field.

Keywords: Ionic liquid; Titanium dioxide; Graphene oxide; Electrochemical sensor; Dopamine

\section{$\underline{\text { FULL TEXT }}$}


(C) 2016 The Authors. Published by ESG (www.electrochemsci.org). This article is an open access article distributed under the terms and conditions of the Creative Commons Attribution license (http://creativecommons.org/licenses/by/4.0/). 